ventricular FMR is intrinsically a ventricular disease, known to have limited effectiveness of MV annuloplasty, it is expected that a restrictive annuloplasty might be a definitive option in atrial FMR. Nonetheless, the lack of echocardiographic data is a strong limitation of this study in its purpose to answer the question about optimal therapy and/or eventual implications for catheter-based strategies for addressing the FMR spectrum.

\section{References}

1. Hirji S, Cote C, Javadikasgari H, Malarczyk A, McGurk S, Kaneko T. Atrial functional versus ventricular functional mitral regurgitation: prognostic implications. J Thorac Cardiovasc Surg. 2022;164:1808-15.e4.
2. Deferm S, Bertrand PB, Verbrugghe FH, Verhaert D, Rega F, Thomas JD, et al Atrial functional mitral regurgitation: JACC review topic of the week. $J$ Am Coll Cardiol. 2019;73:2465-76.

3. Kim DH, Heo R, Handshumacher MD, Lee S, Choi YS, Kim KR, et al. Mitral valve adaptation to isolated annular dilation: insights into the mechanism of atrial functional mitral regurgitation. JACC Cardiovasc Imaging. 2019;12: 665-77.

4. Nishimura RA, Otto CM, Bonow RO, Carabello BA, Erwin JP III Fleisher LA, et al. 2017 AHA/ACC focused update of the 2014 AHA/ ACC guideline for the management of patients with valvular heart disease: a report of the American College of Cardiology/American Heart Association task force on clinical practice guidelines. J Am Coll Cardiol. 2017;70: 252-89.

5. Otto CM, Nishimura RA, Bonow RO, Carabello BA, Erwin JP III, Gentile F, et al. $2020 \mathrm{ACC} / \mathrm{AHA}$ guideline for the management of patients with valvular heart disease: a report of the American College of Cardiology/American Heart Association task force on clinical practice guidelines. Circulation. December 20, 2020 [Epub ahead of print].
See Article page 1808.

\section{Commentary: Pathoanatomic differences in functional mitral regurgitation - a guide for future interventions?}

\author{
Robert B. Hawkins, MD, MSc, and \\ J. Hunter Mehaffey, MD, MSc
}

Dr Hirji and colleagues present an analysis comparing different etiologies of functional mitral regurgitation (FMR) in this month's Journal. ${ }^{1}$ They have elected to classify atrial FMR as due to atrial enlargement or heart failure with preserved ejection fraction and ventricular FMR as related to any ventricular dysfunction. Significant baseline differences are notable, reflecting the considerable heterogeneity of FMR patients. The rate of operative mortality was low and not different between the groups. After controlling for differences in demographics and comorbid conditions, ventricular FMR was a predictor of both mid-term mortality (hazard ratio

\footnotetext{
From the Division of Thoracic and Cardiovascular Surgery, Department of Surgery, University of Virginia, Charlottesville, Va.

Disclosures: The authors reported no conflicts of interest.

The Journal policy requires editors and reviewers to disclose conflicts of interest and to decline handling or reviewing manuscripts for which they may have a conflict of interest. The editors and reviewers of this article have no conflicts of interest.

Received for publication Jan 12, 2021; revisions received Jan 12, 2021; accepted for publication Jan 13, 2021; available ahead of print Jan 21, 2021.

Address for reprints: Robert B. Hawkins, MD, MSc, Division of Thoracic and Cardiovascular Surgery, University of Virginia, PO Box 800679, Charlottesville, VA, 22908 (E-mail: rbh6x@virginia.edu).

J Thorac Cardiovasc Surg 2022;164:1817-8

$0022-5223 / \$ 36.00$

Copyright (C) 2021 by The American Association for Thoracic Surgery

https://doi.org/10.1016/j.jtcvs.2021.01.054
}

Check for updates

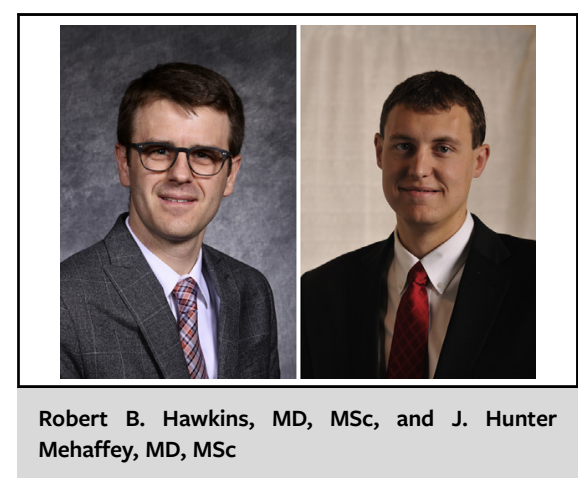

CENTRAL MESSAGE

Ventricular and atrial functional

mitral regurgitation are separate entities with different long-term

outcomes, necessitating pathoa-

natomic definitions to determine

optimal interventions on this

heterogenous group of patients.

[HR], 1.8) and a composite of mortality or reoperation (HR, 2.1). Although these are logical divisions, they paint an incomplete picture because they do not account for other morphological features of the heart that determine the trajectory of functional mitral regurgitation. The degree of annular dilation, ventricular dysfunction, and dilation and leaflet tethering all affect patient outcomes. Although underpowered to assess each of these features, it is a missed opportunity and should be a focus of future studies. 
Although patients with preserved ejection fractions were largely excluded from percutaneous FMR trials, the findings mirror the MitraClip trial data. ${ }^{2}$ The Cardiovascular Outcomes Assessment of the MitraClip Percutaneous Therapy for Heart Failure Patients with Functional Mitral Regurgitation trial (COAPT) found a survival benefit but the Multicentre Study of Percutaneous Mitral Valve Repair MitraClip Device in Patients with Severe Secondary Mitral Regurgitation (MITRA-FR) did not. ${ }^{3,4}$ The patients in MITRA-FR had greater ventricular dysfunction and dilation, with resultant leaflet tethering. No strong conclusions can be made based on this data, but it would suggest this area is critical to future investigation. FMR pathoanatomic classification will help guide the utility of percutaneous interventions, but future research needs to evaluate the relative benefits compared with surgical intervention. These patients have poor long-term outcomes, making research into optimal care all the more important.

A critical area needing improvement in retrospective studies of FMR is the lack of serial echocardiographic follow-up. In this analysis, only $44 \%$ of patients had either echocardiographic or cardiology follow-up after
30 days. These studies often have few patients and low power, making surrogate endpoints, such as recurrent mitral regurgitation, helpful in determining the success of different interventions. Although not commonly performed, serial echocardiography data is best analyzed by longitudinal mixed-effects modeling. ${ }^{5}$ Incorporation of pathoanatomic features, improved follow-up, and comparison of surgical and percutaneous interventions are necessary to personalize interventions in a heterogenous group of patients with functional mitral regurgitation.

\section{References}

1. Hirji S, Cote C, Javadikasgari H, Malarczyk A, McGurk S, Kaneko T. Atrial functional versus ventricular functional mitral regurgitation: prognostic implications. $J$ Thorac Cardiovasc Surg. 2022;164:1808-15.e4.

2. Badhwar V, Alkhouli M, Mack MJ, Thourani VH, Ailawadi G. A pathoanatomic approach to secondary functional mitral regurgitation: evaluating the evidence. $J$ Thorac Cardiovasc Surg. 2019;158:76-81.

3. Stone GW, Lindenfeld J, Abraham WT, Kar S, Lim DS, Mishell JM, et al. Transcatheter mitral-valve repair in patients with heart failure. $N$ Engl J Med. 2018;379: 2307-18.

4. Obadia JF, Messika-Zeitoun D, Leurent G, Iung B, Bonnet G, Piriou N, et al. Percutaneous repair or medical treatment for secondary mitral regurgitation. $N$ Engl J Med. 2018;379:2297-306.

5. Laird NM, Ware JH. Random-effects models for longitudinal data. Biometrics. 1982;38:963-74.

\title{
Commentary: A riddle wrapped in a mystery inside an enigma
}

\author{
Jay K. Bhama, MD
}

Hirji and colleagues ${ }^{1}$ from Brigham and Women's Hospital report their nearly 20-year experience with mitral valve surgery in patients with atrial functional mitral regurgitation (A-FMR). The study details their experience with 94 patients who underwent mitral valve surgery in the setting of atrial fibrillation or left atrial dilatation

\footnotetext{
From the Division of Cardiovascular Surgery, University of Arkansas for Medical Sciences, and Department of Cardiothoracic Surgery, Baptist Heart Failure and Transplant Institute, Baptist Health Medical Center, Little Rock, Ark.

Disclosures: The author reported no conflicts of interest.

The Journal policy requires editors and reviewers to disclose conflicts of interest and to decline handling or reviewing manuscripts for which they may have a conflict of interest. The editors and reviewers of this article have no conflicts of interest.

Received for publication Jan 11, 2021; revisions received Jan 11, 2021; accepted for publication Jan 11, 2021; available ahead of print Jan 20, 2021.

Address for reprints: Jay K. Bhama, MD, Division of Cardiovascular Surgery, University of Arkansas for Medical Sciences, 4301 W Markham St, Little Rock, AR 72205-7199 (E-mail: jbhama@uams.edu).

J Thorac Cardiovasc Surg 2022;164:1818-9

$0022-5223 / \$ 36.00$

Copyright (c) 2021 by The American Association for Thoracic Surgery

https://doi.org/10.1016/j.jtcvs.2021.01.041
}

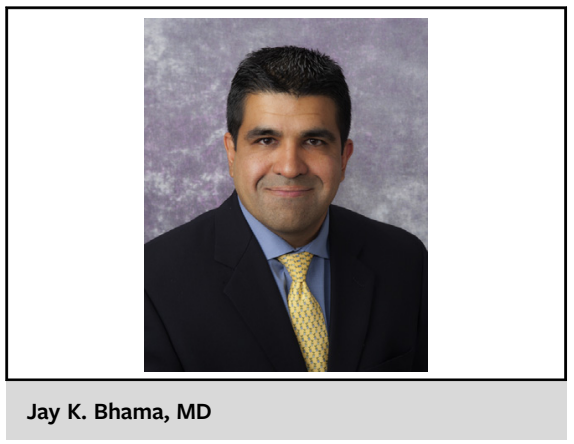

CENTRAL MESSAGE

Atrial functional mitral regurgi-

tation is an important prognostic

indicator in patients being

treated surgically for mitral

regurgitation. 